\title{
Diagnósticos e intervenções de enfermagem em vítimas de trauma durante atendimento pré-hospitalar utilizando a CIPE $^{\circledR}$
}

Nursing diagnoses and interventions in trauma victims during prehospital care using the ICNP ${ }^{\circledR}$

Diagnósticos e intervenciones de enfermería en víctimas de trauma durante atención prehospitalaria utilizando la $\mathrm{CIPE}^{\circledR}$

Thaís Honório Lins' ${ }^{1}$ Ana Xênia Buarque Coelho de Lima ${ }^{2}$, Regina Célia Sales Santos Veríssimo ${ }^{3}$, Janine Melo de Oliveira ${ }^{4}$

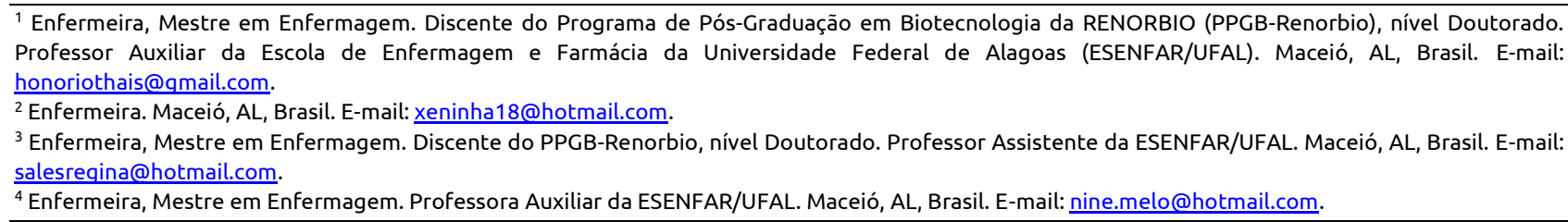

\section{RESUMO}

O presente estudo de abordagem descritiva e quantitativa teve como objetivo identificar diagnósticos e intervenções de enfermagem baseados na CIPE $^{\circledR}$ versão 2011 em vítimas de trauma atendidas por um serviço de atendimento móvel pré-hospitalar em Maceió-AL durante julho de 2010. Foram formulados 33 diagnósticos e 14 intervenções. Destacam-se os diagnósticos "ferida por arma de fogo atual" e "sistema cardiovascular e respiratório comprometido" por evidenciarem a natureza dos agravos atendidos pelo serviço. Entre as intervenções sobressaem-se: "implementar oxigenoterapia por máscara de oxigênio" e "restabelecer sistema cardiovascular e respiratório com manobras de ressuscitação". Conclui-se que a identificação de diagnósticos e intervenções de enfermagem CIPE ${ }^{\circledR}$ mais frequentes em vítimas de trauma durante atendimento pré-hospitalar pode contribuir em cuidados mais direcionados e sistematizados, além de favorecer a documentação de enfermagem.

Descritores: Enfermagem em Emergência; Terminologia; Diagnóstico de Enfermagem; Cuidados de Enfermagem; Atendimento de Emergência Pré-hospitalar.

\section{ABSTRACT}

The objective of this descriptive and quantitative study was to identify nursing diagnoses and interventions based on the ICNP ${ }^{\circledR}$ version 2011 in trauma victims assisted by a mobile prehospital care service in Maceió, Alagoas, in July 2010. A total of 33 diagnoses and 14 interventions were formulated. The following diagnoses stood out "current gunshot wound" and "compromised cardiovascular and respiratory system" because they evidence the nature of the conditions that were cared by the service. Among the interventions, the following stood out: "to implement oxygen therapy using an oxygen mask" and "reestablish the cardiovascular and respiratory system with resuscitation maneuvers". In conclusion, the identification of the most frequent ICNP® nursing diagnoses and interventions among trauma victims during the prehospital service can contribute with offering care that is better directed and systemized, in addition to improving nursing documentation.

Descriptors: Emergency Nursing; Terminology; Nursing Diagnosis; Nursing Care; Emergency Medical Services.

\section{RESUMEN}

Estudio de abordaje descriptivo y cuantitativo que tuvo por objetivo identificar diagnósticos e intervenciones de enfermería basados en la CIPE ${ }^{\circledR}$ versión 2011 en víctimas de trauma atendidas en servicio de emergencias móvil prehospitalario en Maceió-AL durante julio de 2010. Fueron formulados 33 diagnósticos y 14 intervenciones. Se destacaron los diagnósticos "herida por arma de fuego" y "sistemas cardiovascular y respiratorio comprometidos" por evidenciar la naturaleza de los daños atendidos por el servicio. Entre las acciones, sobresalen: "implementar oxigenoterapia por máscara de oxígeno" y "restablecer sistema cardiovascular y respiratorio con maniobras de resucitación". Se concluye en que la identificación de diagnósticos e intervenciones de enfermería CIPE ${ }^{\circledR}$ más frecuentes en víctimas de trauma durante la atención prehospitalaria puede contribuir a efectuar cuidados mejor orientados y sistematizados, además de favorecer la documentación de enfermería.

Descriptores: Enfermería de Urgencia; Terminología; Diagnóstico de Enfermería; Atención de Enfermería; Servicios Médicos de Urgencia. 


\section{INTRODUÇÃO}

O perfil epidemiológico brasileiro mostra que as causas externas estão entre as líderes na lista de mortalidade e morbidade nas últimas quatro décadas ${ }^{1)}$, representando a segunda causa de morte no Brasil, sendo os acidentes e os homicídios os maiores responsáveis por este aumento(2).

Como exemplo desses números encontramos os acidentes de trânsito que, no ano 2007, foram de 383.371, com número de acidentados igual a 513.510, o que projeta, em média, 1.406 acidentes/dia e 1.369 vítimas/dia (1,30 vítima por acidente), significando 15,5\% das hospitalizações por lesões, o que mostra o impacto desse trauma ${ }^{(3)}$.

O trauma acarreta consequências sociais e econômicas tanto para os indivíduos quanto para a sociedade. As lesões relacionadas a ele podem ocasionar incapacidades físicas e ou mentais, temporárias ou permanentes e também levar ao óbito(4).

Estudo aponta que o tempo decorrido entre o acidente e o atendimento hospitalar é um fator decisivo para reduzir a mortalidade e a ocorrência de sequelas, uma vez que $40 \%$ dos óbitos ocorrem na fase préhospitalar ${ }^{(4)}$, em face destas características, para o atendimento neste cenário, há a necessidade de profissionais capacitados ${ }^{(2)}$.

Destaca-se que, no Brasil, a implantação dos serviços de atendimento pré-hospitalar (APH) ocorreu no início da década de 90, o qual passou a ser denominado de Serviço de Atenção Móvel de Urgência (SAMU), a partir do Plano Nacional de Atendimento à Urgência e Emergência em $2003^{(5)}$.

Segundo o Ministério da Saúde, o APH pode ser definido como a assistência prestada em um primeiro nível de atenção aos portadores de quadros agudos, de natureza clínica, traumática ou psiquiátrica, que possa levar a sofrimento, sequelas ou mesmo à morte, provendo um atendimento e/ou transporte adequado a um serviço de saúde hierarquizado, regulado e integrante do Sistema Estadual de Urgência e Emergência ${ }^{(6)}$.

O SAMU é o principal componente da Política Nacional de Atenção às Urgências que tem como finalidade proteger a vida das pessoas e garantir a qualidade no atendimento no Sistema Único de Saúde, de acordo com seus princípios doutrinários, a universalidade, a equidade e a integralidade ${ }^{(7)}$.
Atualmente no Brasil o APH está estruturado em duas modalidades: o Suporte Básico de Vida (SBV) e o Suporte Avançado de Vida (SAV). O SBV consiste na preservação da vida, sem manobras invasivas, em que o atendimento é realizado por pessoas treinadas em primeiros socorros e atuam sob supervisão médica. Já o SAV tem como características manobras invasivas, de maior complexidade e, por este motivo, esse atendimento é realizado exclusivamente por médico e enfermeira. Assim, a atuação da enfermeira está justamente relacionada à assistência direta ao paciente grave sob risco de morte ${ }^{(8)}$.

Vale ressaltar que a área de urgência e emergência tem exigido dos enfermeiros uma nova forma de atuação, tornando-se necessário o rompimento com um modelo de trabalho tradicional cujas tarefas, em sua maioria, são baseadas no modelo de assistência biomédico e centradas em rotinas e tarefas, o qual não tem dado solução às necessidades humanas do paciente crítico(2).

Neste contexto a padronização da assistência às vítimas de trauma é de grande importância e vem sendo realizada pelas instituições de saúde, no Brasil, há mais de vinte anos. No entanto, a necessidade de individualizar a assistência é realidade vivenciada por todos os profissionais que participam desses atendimentos, devido às diferentes formas de apresentação, gravidade e complexidade dos mesmos e, nesse sentido, a utilização da sistematização da assistência de enfermagem (SAE) parece caminho interessante e útil para a atuação no cenário da emergência ${ }^{(9)}$.

A SAE é uma ferramenta essencial no trabalho do enfermeiro, proporcionando recursos técnicos, científicos e humanos, no qual visa uma melhor qualidade de assistência ao cliente e possibilita o seu reconhecimento e valorização(10).

No âmbito dessa reflexão, a SAE, reconhecido instrumento que favorece a organização do processo de cuidar, é tema atual das discussões da área, pois, apesar das diretrizes legais regulamentadas pela Resolução 358/2009 do Conselho Federal de Enfermagem ${ }^{(2)}$, ainda são incipientes as experiências de sucesso(11).

Como metodologia de trabalho e uma ponte à autonomia, o processo de enfermagem, tornou-se um desafio para a qualidade da assistência devido às inovações científicas que o processo de cuidar propõe e 
as particularidades operacionais que cada etapa sugere ${ }^{(12)}$.

O processo de enfermagem desenvolve-se em um processo de cinco fases sequenciais e inter-relacionadas (histórico, diagnóstico, planejamento, implementação e avaliação), coerentes com a evolução da profissão e que quando levado para o APH molda-se a biomecânica e ao ABCDE do trauma podendo então ser aplicado em um serviço de atendimento móvel de urgência ${ }^{(11,13)}$.

Especificamente no atendimento avançado préhospitalar de vítimas de trauma que exige do enfermeiro raciocínio ágil na tomada de decisão clínica para atingir os objetivos do cuidado, o processo de enfermagem é um instrumento essencial por promover um guia sistematizado para o desenvolvimento do julgamento clínico ${ }^{(13)}$.

A aplicação do processo de enfermagem proporciona ao enfermeiro a possibilidade da prestação de cuidados individualizados, centrada nas necessidades humanas básicas, e, além de ser aplicado à assistência, pode nortear a tomada de decisão em diversas situações vivenciadas pelo enfermeiro enquanto gerenciador da equipe de enfermagem ${ }^{(14)}$.

Dentre os elementos que caracterizam o processo de cuidar, destaca-se o diagnóstico de enfermagem, isto é, o julgamento realizado pelo enfermeiro acerca de um fenômeno da prática profissional, que é foco da intervenção de enfermagem ${ }^{(15)}$.

O estabelecimento de diagnósticos de enfermagem é ação privativa do enfermeiro, e permite, em sua elaboração, a composição de uma ampla rede documental de informações codificadas, de conceitos e evidências científicas, que certamente contribuem para o delineamento de conhecimentos da profissão, sobretudo na escolha de intervenções e resultados esperados ${ }^{(2)}$.

Os diagnósticos de enfermagem proporcionam a base para a seleção de intervenções de enfermagem para atingir resultados pelos quais a enfermagem é responsável, sobretudo junto a vítimas graves e de maior complexidade ${ }^{(16-17)}$.

Estudar as causas e as consequências de uma doença é essencial, a fim de estabelecer diagnóstico e contribuir para a adoção de medidas de prevenção, controle, assistência e educação ${ }^{(18)}$. Além disso, mostra-se coerente com o perfil de morbimortalidade nacional, além de fornecer subsídios para a atuação com maior segurança e estímulo à pesquisa ${ }^{(14)}$.

Considerando a complexidade do trauma, a atual epidemiologia brasileira, a incipiente literatura sobre o tema e as especificidades do atendimento às vítimas de trauma no APH desenvolveu-se a atual investigação com o objetivo de identificar a frequência de diagnósticos e intervenções de enfermagem, em pacientes adultos vítimas de trauma atendidas pelo serviço de atendimento móvel de urgência, através da análise das evoluções de atendimento de enfermagem.

\section{METODOLOGIA}

Trata-se de um estudo transversal, com análise documental retrospectivo, de caráter descritivo e abordagem quantitativa, que utilizou dados do serviço de atendimento móvel de urgência - SAMU do município de Maceió, AL referente ao período de julho de 2010.

A escolha desse cenário ocorreu pelo fato deste serviço ser referência no atendimento pré-hospitalar ao trauma e ser representativo da realidade dos sujeitos, proporcionando informações fidedignas.

Para coleta de dados foram selecionadas todos as fichas de atendimento a vítimas de trauma na faixa etária de 18 a 59 anos de idade no mês de julho de 2010 atendidas pela Unidade de Suporte Avançado (USA), excluindo assim, as fichas de atendimento clínico e as fichas de atendimento as crianças e idosos com histórico de trauma. A escolha da faixa etária de 18 a 59 anos é pelo fato de ser a maior população acometida pelo trauma, principalmente $o$ adulto jovem.

Os dados foram coletados utilizando um instrumento semiestruturado fundamentado nos componentes do Modo Fisiológico de Callista Roy ${ }^{(19)}$. A partir das fichas de atendimento foram analisados os registros de enfermagem e identificados os diagnósticos e intervenções realizados no atendimento à vítima de trauma. Para composição das declarações de diagnósticos de enfermagem e intervenções de enfermagem utilizouse o Modelo 7 Eixos da CIPE®, fundamentado na norma ISO 18.104 seguindo as recomendações do Conselho Internacional de Enfermeiros (CIE).

Após a coleta dos dados, esses foram armazenados e tabulados em planilha eletrônica. Quanto à análise descritiva, os cálculos foram realizados com o auxílio do programa estatístico Epi Info (Centers for Disease Control 
and Prevention - CDC) versão 3.5.2 e apresentados na forma de textos, gráfico e tabelas.

Foi realizado na sede administrativa do Serviço de Atendimento Móvel de Urgência - SAMU do município de Maceió - $A L$, por uma das pesquisadoras, após aprovação pelo Comitê de Ética em Pesquisa da Universidade Federal de Alagoas (protocolo 028349/2010-16) e em concordância com à Resolução 196/96 do Conselho Nacional de Saúde.

\section{RESULTADOS}

Foram incluídos nesta pesquisa 67 (13,45\%) relatórios de atendimento de enfermagem à vítimas de trauma com idades de 18 a 59 anos atendidas pela Unidade de Suporte Avançado, no período de julho de 2010. O total do mês em atendimentos à trauma no geral, se constituiu de 498 atendimentos.

A Tabela 1 apresenta os dados de caracterização da amostra, incluindo a distribuição por sexo, idade e o consumo de álcool.

Tabela 1: Caracterização das vítimas de trauma atendidas pelo SAMU. Maceió, AL, 2010.

\begin{tabular}{|c|c|}
\hline Características & Frequência \\
\hline \multicolumn{2}{|l|}{ Sexo } \\
\hline Masculino & $76 \%$ \\
\hline Feminino & $8 \%$ \\
\hline Não registrado & $16 \%$ \\
\hline \multicolumn{2}{|l|}{ Idade } \\
\hline $18-27$ & $33 \%$ \\
\hline $28-37$ & $31 \%$ \\
\hline $38-47$ & $14 \%$ \\
\hline $48-59$ & $13 \%$ \\
\hline Não registrado & $9 \%$ \\
\hline \multicolumn{2}{|l|}{ Abuso de álcool } \\
\hline Alcoolizados & $16 \%$ \\
\hline Não alcoolizados & $84 \%$ \\
\hline
\end{tabular}

O Gráfico 1 apresenta o tipo de trauma sofrido pelas vítimas de trauma, segundo relatório próprio do Serviço de Atendimento Móvel de Urgência.

Gráfico 1: Tipo de injúria sofrida pelas vítimas atendidas pelo SAMU. Maceió, AL, 2010.

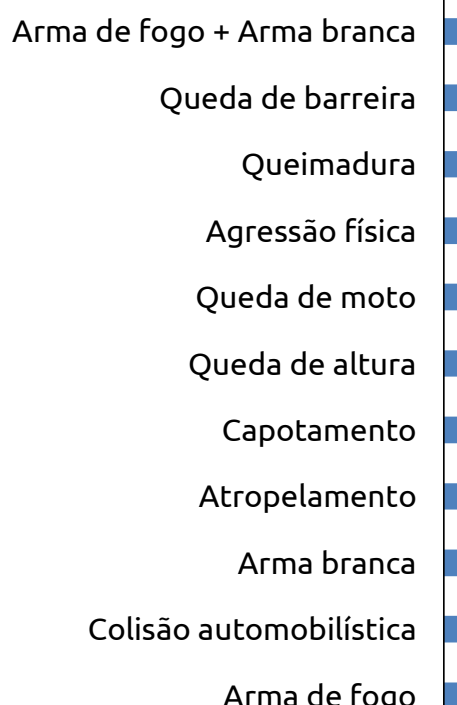

Arma de fogo

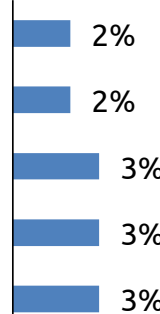

$3 \%$ 
Quanto aos diagnósticos e intervenções de enfermagem, elaborados a partir de identificação de termos dos CIPE $^{\circledR}$ nos relatórios de enfermagem, ocorreram num total de 33 diagnósticos e 14 intervenções, que traduziram o perfil dos atendimentos atendidos pelo serviço de atendimento móvel em Maceió, AL. (Tabelas 2 e 3 ).

Tabela 2: Distribuição dos diagnósticos de enfermagem segundo a CIPE ${ }^{\circledR}$ versão 2011, identificados nas vítimas de trauma atendidas pelo SAMU, segundo a frequência de surgimento. Maceió, AL, 2010.

\begin{tabular}{|c|c|c|}
\hline Diagnóstico de Enfermagem & $\mathbf{N}$ & Frequência \\
\hline Estado de consciência normal & 24 & $35,82 \%$ \\
\hline Ferida por arma de fogo atual & 22 & $32,83 \%$ \\
\hline Perda sanguínea potencial & 16 & $23,88 \%$ \\
\hline Abuso de álcool & 11 & $16,41 \%$ \\
\hline Ferida traumática atual por faca & 9 & $13,43 \%$ \\
\hline Fratura atual & 9 & $13,43 \%$ \\
\hline Dor aguda & 8 & $11,94 \%$ \\
\hline Estado de consciência diminuído & 8 & $11,94 \%$ \\
\hline Escoriação grave & 7 & $10,44 \%$ \\
\hline Comunicação verbal efetiva & 5 & $7,46 \%$ \\
\hline Comunicação verbal comprometida & 4 & $5,97 \%$ \\
\hline Lesão atual & 4 & $5,97 \%$ \\
\hline Ventilação espontânea comprometida & 4 & $5,97 \%$ \\
\hline Sistema cardiovascular e respiratório comprometida & 4 & $5,97 \%$ \\
\hline Trauma grave na cabeça & 3 & $4,47 \%$ \\
\hline Laceração grave & 3 & $4,47 \%$ \\
\hline Pulso radial em nível esperado & 2 & $2,98 \%$ \\
\hline Risco de termorregulação comprometida & 2 & $2,98 \%$ \\
\hline Tentativa de suicídio & 2 & $2,98 \%$ \\
\hline Ventilação espontânea efetiva & 2 & $2,98 \%$ \\
\hline Agitação moderada & 2 & $2,98 \%$ \\
\hline Dentição comprometida & 1 & $1,49 \%$ \\
\hline Confusão moderada & 1 & $1,49 \%$ \\
\hline Paresia atual em parte inferior do corpo & 1 & $1,49 \%$ \\
\hline Episódio de vômito moderado durante o transporte & 1 & $1,49 \%$ \\
\hline Contusão atual & 1 & $1,49 \%$ \\
\hline Atitude dificultadora face aos cuidados & 1 & $1,49 \%$ \\
\hline Congestão de sangue em região do olho & 1 & $1,49 \%$ \\
\hline Queimadura total do corpo & 1 & $1,49 \%$ \\
\hline Tremor moderado & 1 & $1,49 \%$ \\
\hline Exposição a contaminação do intestino pela ferida traumática & 1 & $1,49 \%$ \\
\hline Perfusão dos tecidos periféricos efetiva & 1 & $1,49 \%$ \\
\hline Perfusão dos tecidos periféricos interrompida & 1 & $1,49 \%$ \\
\hline
\end{tabular}


Tabela 3: Distribuição das intervenções de enfermagem segundo a CIPE ${ }^{\circledR}$ versão 2011 , identificados nas vítimas de trauma atendidas pelo SAMU, segundo a frequência de surgimento. Maceió, AL, 2010.

\begin{tabular}{ccc}
\hline Intervenção de Enfermagem & N & Frequência \\
\hline Transportar a vítima para serviço de urgência & 43 & $6,41 \%$ \\
Imobilizar o doente com dispositivos de imobilização & 32 & $4,77 \%$ \\
Instalar acesso intravenoso para administrar solução & 30 & $4,47 \%$ \\
Implementar oxigeno terapia por máscara de oxigênio & 29 & $4,32 \%$ \\
Comprimir e cobrir com compressa o local da lesão & 10 & $1,49 \%$ \\
Administrar medicamento por via intravenosa & 8 & $11,94 \%$ \\
Monitorizar status cardíaco utilizando o monitor cardíaco & 4 & $5,97 \%$ \\
Aspirar vias aéreas & 4 & $5,97 \%$ \\
Promover a termo regulação adequada com coberta & 3 & $4,47 \%$ \\
Restabelecer sistema cardiovascular e respiratórios com manobras de ressuscitação & 3 & $4,47 \%$ \\
Intubar o doente & 3 & $4,47 \%$ \\
Restringir o doente & 2 & $2,98 \%$ \\
Cobrir com compressa embebida em solução o local da lesão & 1 & $1,49 \%$ \\
\hline
\end{tabular}

\section{DISCUSSÃO}

A epidemiologia do trauma no Brasil tem mostrado que as maiores incidências estão sobre pessoas em idade produtiva. Na ampla faixa etária dos 18 aos 39 anos de idade, evidenciado no estudo, as causas externas ocupam o primeiro lugar como causa de morte $20-21)$.

Quanto ao sexo, os homens são muito mais acometidos por trauma que as mulheres. Neste estudo os homens foram mais de nove vezes mais acometidos que as mulheres. Segundo dados do Departamento Estadual de Trânsito de Alagoas (DETRAN-AL), no ano de 2010, $80 \%$ dos atendimentos que deram entrada em um hospital estadual de referência em atendimento de urgência e emergência, foram do sexo masculino(21). Isto pode estar relacionado ao fato de maior exposição aos riscos de acidentes automobilísticos, violência, entre outros.

Assim sendo, esses dados nos levam a refletir sobre os padrões socioculturais, em relação a questões de gênero, que se perpetuam em nossa sociedade e terminam por conduzir a altas taxas de morbimortalidade em adultos jovens do sexo masculino, no auge de suas capacidades, acarretando prejuízos econômicos consideráveis à nação(22).

Os acidentes de trânsito e os homicídios são os dois subgrupos responsáveis por mais da metade dos óbitos por acidentes e violência ${ }^{(20)}$. Nesse sentido, pode-se notar a alta frequência de vítimas atendidas por tais injúrias, evidenciando o despreparo e a falta de cuidado no trânsito, como também a acessibilidade de civis a armas de fogo.

As formas de violência em Maceió se apresentam como dado preocupante, por ser a capital do Estado que ocupa posição alarmante, sendo o mais violento no Brasil, com a média de 60,3 homicídios para cada 100 mil habitantes, segundo publicação do Ministério da Justiça(23).

Outro importante dado se refere ao uso de álcool, pois $16 \%$ das vítimas atendidas estavam alcoolizadas. Fato importante é a associção do álcool com o gênero. Das ocorrências em que o uso de álcool foi relatado, em $13 \%$ delas foram somente do sexo masculino, entre a faixa etária de 25 a 53 anos, o que reflete o maior consumo de álcool pelos homens.

O consumo abusivo e/ou inadequado desta substância pode trazer consequências orgânicas, psicológicas e sociais graves. Entre estas consequências estão as ocorrências de lesões por causas externas, sobretudo acidentes ou violência, conceituadas pela "Política Nacional de Redução da Morbimortalidade por Acidentes e Violência" como o conjunto das ocorrências que matam ou geram agravos à saúde e que demandam atendimento nos serviços de saúde(24).

Especificamente no atendimento avançado préhospitalar de vítimas de trauma que exige do enfermeiro raciocínio ágil na tomada de decisão clínica para atingir os objetivos do cuidado, o processo de enfermagem é um instrumento essencial por promover um guia 
sistematizado para o desenvolvimento do julgamento clínico $^{(25)}$.

Dentre os diagnósticos encontrados os "ferida por arma de fogo", "perda sanguínea potencial", "ferida traumática atual por faca", "fratura", "sistema cardiovascular e respiratório comprometidos" e "trauma grave na cabeça" evidencia a natureza dos agravos que são atendidos por tal serviço como a parada cardiorrespiratória e a lesão cerebral traumática.

Em estudo realizado na cidade de São Paulo, com o objetivo de conhecer a frequência dos diagnósticos de enfermagem em vítimas de trauma, nas primeiras seis horas após o evento traumático, com base na linguagem da North American Nursing Diagnosis Association (NANDA) os diagnósticos mais frequentes foram: risco de infecção, integridade da pele prejudicada, dor aguda e conforto prejudicado(1).

Quanto aos diagnósticos de maior frequência no estudo, destacam-se o "estado de consciência normal" que corresponde à resposta mental a impressões resultantes de uma combinação dos sentidos, mantendo a mente alerta e sensível ao ambiente exterior. Nos 24 pacientes que apresentaram tal diagnóstico, seu nível de consciência estava adequado, não apresentando nenhum dano neurológico no momento da avaliação(25).

A identificação deste diagnóstico pode ocorrer com o auxílio de perguntas simples, e no caso de respostas coerentes através de frases completas, o enfermeiro poderá concluir que o paciente está com as vias aéreas liberadas, apresentando funções respiratórias suficientes que permitem a fala, perfusão cerebral adequada e funcionamento neurológico razoável(19).

Os efeitos de projéteis de arma de fogo no ser humano evidenciados pelo diagnóstico "ferida por arma de fogo", são divididos em dois tipos: ação direta e ação indireta. A ação direta refere-se ao impacto do projeto, que empurra e lesiona os tecidos, deslocando-os. Na ação indireta forma-se a cavidade permanente, que é o ferimento provocado pelo projétil ao romper os tecidos: caracteriza-se por uma área de necrose localizada, proporcional ao tamanho do projétil que atingiu os tecidos. O segundo é denominado cavidade temporária, produzida pelo intenso choque do projétil na massa líquida dos tecidos. Os tecidos elásticos como os músculos, vasos sanguíneos e pele, são retraídos após a passagem do projétil voltando depois à sua posição normal ${ }^{(19)}$.

O diagnóstico "perda sanguínea potencial" pode ter seu julgamento alterado a depender da gravidade da hemorragia. Achados de extrema importância clínica, para os personagens que atuam no setor de emergência, referem-se aos quatro diagnósticos de enfermagem relacionados à reposição volêmica e controle de hemorragia, representados por risco de choque, risco de sangramento, débito cardíaco diminuído e risco de perfusão cerebral ineficaz (uma vez que está relacionado à quantidade de volume circulante) ${ }^{(14)}$.

O uso abusivo de álcool presente no diagnóstico "abuso de álcool", favorece o risco de acidentes de trânsito devido aos efeitos que exerce no organismo, proporcionando aos motoristas um falso senso de confiança, prejudicando habilidades como atenção, coordenação e tempo de reação. Pois, cerca de um terço de pacientes vítimas de lesões de causas externas, ingeriu bebidas alcoólicas antes do trauma, sendo a causa externa mais frequente, o acidente de trânsito(24).

Nos diagnósticos de enfermagem em que 0 enfermeiro está diante de uma vítima de agressão por arma branca ("ferida traumática por faca"), é necessárioo a avaliação quanto ao trajeto da arma, pois a depender do local de inserção do projétil, sistemas corporais importantes para o equilíbrio da hemodinâmica corporal poderão ser afetados, contribuindo para a piora do paciente.

Outro diagnóstico de importância no atendimento pré-hospitalar é o "sistema cardiovascular e respiratório comprometidos", correspondente aos pacientes que apresentaram parada cardiorrespiratória (PCR) que pode ser definida como a cessação da circulação e da respiração reconhecida pela ausência de batimentos cardíacos e da respiração em um paciente inconsciente. As diretrizes para a conduta diante de uma PCR foram recentemente revistas e publicadas pela American Heart Association em 2010.

As intervenções de enfermagem encontradas e traduzidas para a CIPE $^{\circledR}$ revelam as medidas utilizadas pelo serviço para a manutenção da vida até a chegada ao local de tratamento definitivo e, que sem elas, vidas poderiam ser perdidas.

Dentre as intervenções encontradas os "transportar a vítima para serviço de urgência”, "imobilizar o doente 
com dispositivos de imobilização", "instalar acesso intravenoso para administrar solução", "implementar oxigenoterapia por máscara de oxigênio", "comprimir e cobrir com compressa o local da lesão" e "administrar medicamento por via intravenosa" evidenciam os diferentes meios que a equipe do APH móvel avançado utiliza para a manutenção e recuperação das vítimas de trauma.

A intervenção "transportar a vítima para serviço de urgência" corresponde a identificação de alguma condição que ameace a vida durante o exame primário, sendo o paciente rapidamente imobilizado para o transporte, após o início da intervenção na cena. O transporte deve começar tão logo o doente esteja dentro da ambulância e estabilizado. Рага alguns pacientes críticos, o inicio do transporte é o aspecto mais importante do tratamento definitivo no local ${ }^{(8)}$.

Ao transportar o doente o que deve ser adotado a princípio é "não causar dano adicional" na escolha da forma de transporte do doente. Os transportes terrestre, aquático e aéreo podem ser seguros e efetivos em realizar este princípio. Fatores locais tais como disponibilidade, localização da ocorrência em relação ao hospital de referência, custo e clima são importantes para determinar a escolha ${ }^{(19)}$.

A intervenção "imobilizar o doente com dispositivos de imobilização" corresponde a estabilização da vítima por meio de instrumentos que visem diminuição da mobilidade e assim, das consequências delas, como por exemplo, pranchas rígidas, talas, tirantes, colares cervicais e imobilizadores de cabeça (head-block).

Os mecanismos de lesão podem auxiliar a determinar a necessidade de imobilização da coluna. Sabe-se que a manipulação incorreta de uma vítima de trauma por pessoas não treinadas pode causar lesão adicional à coluna, sendo essa iatrogenia causada pela imperícia no procedimento. Assim, o fato de uma vítima deambular no local do acidente, não afasta a necessidade de uma imobilização adequada. Sempre que se suspeite de uma lesão de coluna, o doente deve ser imobilizado desde acima até abaixo do local suspeito, até que a presença de fratura tenha sido excluída através de estudos radiológicos ${ }^{(8)}$.

A intervenção "instalar acesso intravenoso para administrar solução" corresponde a realização de venóclise periférica para a reposição volêmica, onde o enfermeiro no APH deverá estar apto para detectar alterações precoces na diminuição do volume de líquidos corporais, com intuito de prevenir o agravamento da situação que pode ocorrer de modo súbito e levando ao prejuízo na manutenção da necessidade hídrica da vítima. Portanto, o enfermeiro realiza intervenções como instalação de catéteres venosos calibrosos para reposição volêmica, sem deixar de preocupar-se com a correção da perda de líquidos, objetivando a melhora da oxigenação dos tecidos e prevenindo a instalação de um quadro irreversível levando a vítima a perder sua vida(2).

O acesso ao sistema vascular deve ser obtido rapidamente, necessitando a utilização de catéteres intravenosos periféricos calibrosos ${ }^{(8)}$.

A intervenção "implementar oxigenoterapia por máscara de oxigênio" corresponde a necessidade do organismo de obter o oxigênio por meio da ventilação, da difusão do oxigênio e dióxido de carbono entre os alvéolos e o sangue, do transporte do oxigênio para os tecidos periféricos e da remoção do dióxido de carbono; e da regulação da respiração com objetivo de produzir energia e manter a vida(2).

Normalmente com relação direta de diagnósticos de enfermagem de sistema respiratório comprometido, ou ventilação espontânea comprometida, que estão relacionados às duas primeiras etapas do atendimento inicial ao politraumatizado, ou seja, estabelecem relações com a desobstrução de vias aéreas, e adequada oferta de oxigênio(14).

A oferta inadequada de sangue oxigenado ao cérebro e a outras estruturas vitais é o fator que mais rapidamente causa a morte do traumatizado. A prevenção da hipoxemia requer uma via aérea protegida e desobstruída e uma ventilação adequada. É imperativo assegurar uma via aérea permeável, administrar oxigênio e proporcionar suporte ventilatório ${ }^{(8)}$.

A intervenção "comprimir e cobrir com compressa o local da lesão" corresponde a prevenção de contaminação a partir da lesão de continuidade da pele, além da compressão do local da lesão visando a diminuição da perda sanguínea.

A compressão direta aplicada sobre o local de sangramento é a técnica inicial empregada para o controle de hemorragia externa, aumentando a pressão extraluminal e, portanto, reduzindo a pressão transluminal, ajudando a diminuir ou parar o 
sangramento. Mesmo se a perda sanguínea não for completamente interrompida, ela pode diminuir até o ponto em que o sistema de coagulação do sangue possa parar a hemorragia dependendo de cada caso(19).

\section{CONCLUSÃO}

Quando se pensa na aplicação do processo de enfermagem ao contexto do atendimento de urgência pré-hospitalar pode-se imaginar um método extenso no que tange a sua execução e o tempo utilizado para ela, traduzindo-se em um consultório com vários papéis para preencher, o que, no ambiente pré-hospitalar jamais poderia ocorrer, e com isso, impossível de se implementar. Contudo, a metodologia proposta pelo processo de enfermagem e suas etapas podem e são incorporadas para o contexto do atendimento de urgência realizado pelo enfermeiro no serviço de atendimento móvel.

As etapas do processo de enfermagem são incorporadas ao ABCDE do trauma, tendo os diagnósticos e as intervenções elaboradas, papel de destaque no atendimento às vítimas de trauma. $A$ avaliação rápida $e$ eficaz realizada pelo enfermeiro em APH fornece subsídios para a elaboração de diagnósticos e intervenções de enfermagem, que são totalmente

\section{REFERÊNCIAS}

1. Sallum AMC, Sousa RMC. Diagnósticos de enfermagem em vítimas de trauma nas primeiras seis horas após o evento. Acta paul. enferm. [Internet]. 2012 [cited 2012 set 18]; 25(2).

Available from:

http://www.scielo.br/scielo.php?script=sci_arttext\&pid=S010321002012000200016\&lng=pt\&nrm=iso.

2. Cyrillo RMZ, Dalri MCB, Canini SRMS, Carvalho EC, Lourencini RR. Diagnósticos de enfermagem em vítimas de trauma atendidas em um serviço pré-hospitalar avançado móvel. Rev. Eletr. Enf. [Internet]. 2009 [cited 2011 out 15];11(4):811-9. Available from:

http://www.fen.ufg.br/revista/v11/n4/pdf/v11n4a06.pdf.

3. Mello JMHP, Koizumi MS. Acidentes de trânsito no Brasil: um atlas de sua distribuição. São Paulo: ABRAMET; 2007.

4. Mock CN, Jurkovich GJ, Amon-Kotei D, Arreola-Risa C, Maier RV. Trauma mortality patterns in three nations at different economic levels: implications for global trauma system development. J Trauma 1998;44(5):804-12.

5. Conselho Nacional de Saúde, Ministério da Saúde. Portaria nº. 1864 de 29 de setembro de 2003. Institui o componente préhospitalar móvel da Política Nacional de Atenção às Urgências. Diário Oficial da União. Brasília (Brasil): Ministério da Saúde; 2003.

6. Portal da Saúde [Internet]. O que é SAMU? [cited 2011 maio 26]. Available from:

http://portal.saude.gov.br/portal/saude/visualizar_texto.cfm?id txt=30273\&janela $=1$. possíveis de serem utilizados na linguagem da $\mathrm{CIPE}^{\circledR}$ Versão 2011.

Este estudo mostra a clara possibilidade da utilização do processo de enfermagem e da $\mathrm{CIPE}^{\circledR}$ no serviço de atendimento móvel. Рara tanto, é indispensável que os coordenadores e enfermeiros de tal serviço tenham disponibilidade interna e aceitem o desafio de inovar suas práticas, buscando junto ao processo de enfermagem, melhorias nas condições da assistência prestada.

A contribuição deste estudo à prática de enfermagem consiste em proporcionar maior precisão na identificação de diagnósticos e intervenções de enfermagem na linguagem $\mathrm{CIPE}^{\circledR}$, para pacientes vítimas de trauma durante atendimento pré-hospitalar.

As limitações do estudo centralizaram-se no uso de fontes secundárias (relatórios de atendimentos e registros de enfermagem) que apesar da amplitude de possibilidades de diagnósticos e de intervenções de enfermagem, registros curtos ou restritos interferiram na elaboração adstrita das composições de diagnósticos e intervenções de enfermagem.

Sugere-se que mais estudos sejam realizados sobre tal temática e que, em estudos próximos, sejam construídos instrumentos que facilitem a realização do processo de enfermagem neste tipo de serviço.

7. Conselho Nacional de Saúde, Ministério da Saúde. Portaria No 316/04 - Qualifica o Serviço de Atendimento Móvel às Urgências - SAMU 192, no município de Maceió (AL), à Rede Nacional de Atenção às Urgências. Brasília (Brasil): Ministério da Saúde; 2004.

8. National Association of Emergency Medical Technicians (U.S.). PHTLS basic and advanced Prehospital Trauma Life Support. 6st ed. St Louis: Mosby; 2007.

8. Remizoski J, Rocha MM, Vall J. Sistematização da assistência de enfermagem-SAE: uma revisão teórica. Cad. da Esc. de Saúde. [Internet]. 2010 [cited 2012 set 18]; 03:01-14. Available from: http://apps.unibrasil.com.br/revista/index.php/saude/article/vie wFile/343/272.

10. Silva MM, Moreira MC. Desafios à sistematização da assistência de enfermagem em cuidados paliativos oncológicos: uma perspectiva da complexidade. Rev. Eletr. Enf. [Internet]. 2010 [cited 2012 set 18];12(3):483-90. Available from: http://www.fen.ufg.br/revista/v12/n3/v12n3a10.htm. 11. Amante LN, Rossetto AP, Schneider DG. Sistematização da assistência de enfermagem em unidade de terapia intensiva sustentada pela teoria de Wanda Horta. Rev. esc. enferm. USP. [Internet]. 2009 [cited 2011 maio 26];43(1):54-64. Available from:

http://www.scielo.br/scielo.php?script=sci arttext\&pid=S008062342009000100007\&lng=pt\&nrm=iso.

12. Silva ES, Souza SR, Ferreira SMS. Sistematização da assistência de enfermagem aos clientes com traumatismo 
raquimedular em uma unidade de neurocirurgia. R. pesq.: cuid. fundam. [Internet]. 2011. jan/mar. 3(1):1542-552.

13. Caritá EC, Nini RA, Melo AS. Sistema de auxílio aos diagnósticos de enfermagem para vítimas de trauma no atendimento avançado pré-hospitalar móvel utilizando as Taxonomias NANDA e NIC. J. Health Inform. 2010 Out-Dez; 2(4):87-94.

14. Sallum AMC, Santos JLF, Lima FD. Diagnósticos de enfermagem em vítimas fatais decorrentes de trauma no cenário da emergência. Rev. Latino-Am. Enfermagem [Internet]. jan.-fev. 2012 [acesso em: 20 set. 2012];20(1):[08 telas]. Available from: http://www.scielo.br/scielo.php?pid=S010.4$11692012000100002 \&$ script=sci abstract\&tlng=pt

15. Silva AF, Nóbrega MMl, Macedo WCM. Diagnósticos/resultados de enfermagem para parturientes e puérperas utilizando a Classificação Internacional para Prática de Enfermagem. Rev. Eletr. Enf. [Internet]. 2012 [cited 2012 set 18];14(2):267-76. Available from:

http://dx.doi.org/10.5216/ree.v14i2.11211.

16. Galdeano LE, Rossi LA. Construção e validação de instrumento de coleta de dados para o período perioperatório de cirurgia cardíaca. Rev. Latino-Am. Enfermagem. 2002;10(6):800-4

17. Carvalho EC. Relações entre a coleta de dados, diagnóstico e prescrição de enfermagem a pacientes adultos de uma UTI. Rev. Latino-Am. Enfermagem. 2008;16(4):700-6.

18. Calil AM, Pimenta CAM. A importância da avaliação e padronização analgésica em serviços de emergência. Acta Paul Enferm. 2010;65(1):132-8.

19. Coutinho APO. Construção e validação de um instrumento para a sistematização da assistência de enfermagem no Serviço de Atendimento Móvel de Urgência (SAMU) [dissertação]. João Pessoa: Universidade Federal da Paraíba/UFP; 2007. 124 p. [cited 2011 mai 02]. Available from:

http://www.dominiopublico.gov.br/pesquisa/DetalheObraForm. do? select action $=\&$ co obra $=60030$.

20. Politica Nacional de REDUÇÃO da Morbimortalidade POR Acidentes e Violência. Rev. Saúde Pública [periódico na Internet]. 2000 [cited 2012 Set 22]; 34(4):427-30. Available from: http://dx.doi.org/10.1590/S0034-89102000000400020.

21. Departamento Estadual de Trânsito de Alagoas [Internet]. Vítimas de acidentes de trânsito: dados do serviço de arquivo médico e estatístico do Hospital Geral do Estado e da Unidade de Emergência do Agreste Dr. Daniel Houly. Ano I, Nº 8, 2010 [cited 2011 jun 15]. Available from:

http://www.detran.al.gov.br/seguranca/acidentes/boletinsinformativos/Boletim 8.pdf.

22. Santos AMR, Moura MLB, Nunes BMVT, Leal CFS, Teles JBM. Perfil das vítimas de trauma por acidente de moto atendidas em um serviço público de emergência. Cad. Saúde Pública [Internet]. 2008 [cited 2011 nov 27];24(8):1927-1938. Available from: http://www.scielo.br/scielo.php?pid=S0102311X2008000800021\&script=sci arttext.

23. Departamento Estadual de Trânsito de Alagoas [Internet]. Relatório de evolução da frota e população: dados de Alagoas e capital. Ano I, Nº, 2001 [cited 2011 jun 15]. Available from: http://www.detran.al.gov.br/seguranca/acidentes/boletinsinformativos/Boletim_6.pdf.

24. Freitas EAM, Mendes ID, Oliveira LCM. Ingestão alcoólica em vítimas de causas externas atendidas em um hospital geral universitário. Rev. Saúde Pública [Internet]. 2008 [cited 2011 out 15];(42).5:813-821. Available from:

http://www.scielo.br/scielo.php?script=sci arttext\&pid=S0034$89102008000500005 \& \operatorname{lng}=$ pt\&nrm=iso.

25. International Council of Nurses. Supporting the development of resources for the International Classification for Nursing Practice. ICNP - Brasileiro. 2011. 132p.
Artigo recebido em 08/12/2011.

Aprovado para publicação em 07/08/2012.

Artigo publicado em 31/03/2013. 